\title{
Efficacy of Combined Thrombomodulin and Antithrombin in Anticoagulant Therapy for Acute Cholangitis-induced Disseminated Intravascular Coagulation
}

\author{
Nozomi Morita ${ }^{1}$, Kazunari Nakahara ${ }^{2}$, Ryo Morita ${ }^{2}$, Keigo Suetani ${ }^{1}$, Yosuke Michikawa ${ }^{2}$, \\ Junya Sato ${ }^{2}$, Kensuke Tsuji ${ }^{2}$, Hiroki Ikeda ${ }^{2}$, Kotaro Matsunaga ${ }^{2}$, Tsunamasa Watanabe ${ }^{2}$, \\ Nobuyuki Matsumoto ${ }^{2}$, Chiaki Okuse ${ }^{1}$, Michihiro Suzuki ${ }^{1}$ and Fumio Itoh ${ }^{2}$
}

\begin{abstract}
:
Objective The efficacy and safety of concomitant use of antithrombin (AT) with recombinant human soluble thrombomodulin (rTM) for acute cholangitis-induced disseminated intravascular coagulation (ACinduced DIC) remains unclear. This study was conducted to investigate the efficacy of AT combined with rTM as anticoagulant therapy for AC-induced DIC.

Methods One hundred patients with AC-induced DIC received anticoagulant therapy using rTM from April 2010 to December 2017. Of the 83 patients treated with rTM immediately after the diagnosis of DIC, excluding those who had not undergone biliary drainage or who had malignancies or a serum AT III level $>70 \%, 56$ patients were studied. Outcomes and adverse events (AEs) were retrospectively compared between the 16 patients treated with rTM alone (rTM group) and the 40 patients treated with rTM and AT (rTM+AT group).

Results Patients' background characteristics did not differ markedly, except for a significantly higher serum D-dimer level in the rTM group than in the rTM+AT group ( $\mathrm{p}=0.038)$. The DIC resolution rates on day 9 were $100 \%$ and $95.1 \%$ in the rTM and rTM+AT groups, respectively ( $\mathrm{p}=0.909)$. The mean DIC scores were significantly lower in the rTM group than in the rTM+AT group on days $3(\mathrm{p}=0.012), 5(\mathrm{p}<0.001), 7(\mathrm{p}=$ $0.033)$, and $9(\mathrm{p}=0.007)$. The incidence of AEs was $6.3 \%$ and $10.0 \%(\mathrm{p}=0.941)$, and the in-hospital mortality rates was $0 \%$ and $5.0 \%(\mathrm{p}=0.909)$ in the $\mathrm{rTM}$ and $\mathrm{rTM}+\mathrm{AT}$ groups, respectively.

Conclusion The concomitant use of AT with anticoagulant therapy using rTM for AC-induced DIC may not help improve the treatment outcome.
\end{abstract}

Key words: disseminated intravascular coagulation, acute cholangitis, thrombomodulin, antithrombin, biliary drainage

(Intern Med 58: 907-914, 2019)

(DOI: 10.2169/internalmedicine.1923-18)

\section{Introduction}

The novel anticoagulant agent recombinant human soluble thrombomodulin (rTM) was recently shown to be effective for infection-related disseminated intravascular coagulation (DIC) (1-4). The efficacy of antithrombin (AT) for DIC has also previously been reported $(5,6)$, and treatment with
rTM and AT recently played an important role in anticoagulant therapy for infection-related DIC in Japan (7). More recently, combination therapy with rTM and AT has been shown to be effective for DIC (8).

Acute cholangitis is an infectious disease caused mainly by a Gram-negative bacillus often associated with DIC. A few reports exist on anticoagulant therapy using rTM for acute cholangitis-induced (AC-induced) DIC (9-11). How-

${ }^{1}$ Department of Gastroenterology and Hepatology, Kawasaki Municipal Tama Hospital, Japan and ${ }^{2}$ Department of Gastroenterology and Hepatology, St. Marianna University, School of Medicine, Japan

Received: August 3, 2018; Accepted: September 12, 2018; Advance Publication by J-STAGE: November 19, 2018

Correspondence to Dr. Kazunari Nakahara, nakahara@marianna-u.ac.jp 


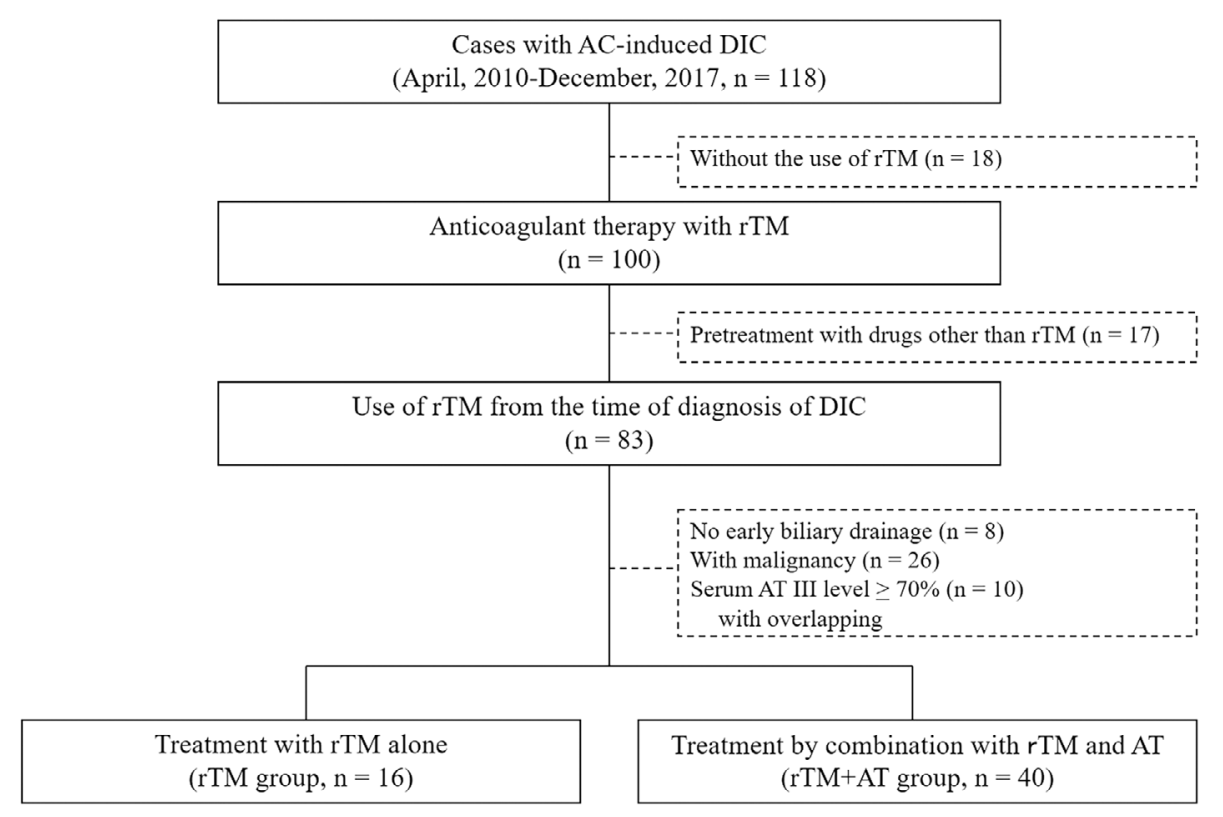

Figure 1. Flowchart of the selection of patient groups. DIC: disseminated intravascular coagulation, AC: acute cholangitis, rTM: recombinant human soluble thrombomodulin, AT: antithrombin

ever, evidence concerning the selection of the most appropriate anticoagulant therapy for this condition is scarce. Although the Tokyo Guidelines 2018 (TG18) for acute cholangitis (12) recommend the use of rTM for the treatment of AC-induced DIC with a low evidence level of D, the efficacy and safety of the concomitant use of AT with rTM remain unclear.

We therefore investigated the efficacy and safety of a combination of AT with anticoagulant therapy using rTM for AC-induced DIC. We previously reported that the use of rTM can lead to an earlier improvement in AC-induced DIC than the non-use of rTM, and early biliary drainage, rTM administration, and a lack of association with malignancy may contribute to an improvement in AC-induced DIC (10). Furthermore, Tamura et al. reported that patients who developed DIC in solid malignant tumors had a worse outcome than those with infection-related DIC (13). Therefore, patients who did not undergo biliary drainage, those with malignancies, and those with a serum AT III level of $>70 \%$ were excluded from our current study.

In the present study, we investigated the efficacy of combination therapy with rTM and AT only for patients with exclusively infection-related DIC caused by AC (excluding potential malignancy-related DIC) who underwent early biliary drainage.

\section{Materials and Methods}

\section{Patients}

From April 2010 to December 2017, 118 patients with a diagnosis of AC-induced DIC were admitted to St. Marianna University School of Medicine Hospital and Kawasaki Municipal Tama Hospital. Of these, 100 patients received anti- coagulant therapy using rTM. Of the 83 patients who received rTM from the time of the diagnosis of DIC, 56 were included as study participants after the exclusion of patients who had not undergone biliary drainage within 24 hours after the diagnosis of DIC, those with malignancies, and those with a baseline serum AT III level of $>70 \%$. These 56 patients were divided into 2 groups: 16 patients who were treated without AT but with rTM (rTM group) and 40 patients who were treated with a combination of AT and rTM (rTM+AT group) (Fig. 1).

The dose of rTM in the rTM group was 380 units $/ \mathrm{kg} /$ day in 13 patients and 130 units/kg/day (a reduced dose due to renal dysfunction) in 3 patients. The mean duration of rTM administration was 4.7 days (range, 3 to 7 ). The dose of rTM in the rTM+AT group was 380 units $/ \mathrm{kg} /$ day in 35 patients and 130 units/kg/day (again, a reduced dose due to renal dysfunction) in 5 patients. The mean duration of rTM administration was 5.4 days (range, 3 to 10). The dose of AT in the rTM+AT group was 500 units $/ \mathrm{kg}$ in all patients, and the mean duration of AT administration was 3.0 days (range, 2 to 5).

The diagnosis and severity grade of AC were determined according to the Tokyo Guidelines 2013 (TG13) (14). A diagnosis of DIC was made when the DIC score was $\geq 4$ according to the DIC diagnostic criteria in Japan (15).

In our hospital, we basically did not perform endoscopic sphincterotomy (EST) but only biliary drainage for the patients who had already been diagnosed with DIC, and all patients who underwent endoscopic retrograde cholangiopancreatography (ERCP) received blood tests $3 \mathrm{~h}$ after ERCP. The patients who underwent EST or Pre-cut in this study did not meet the diagnostic criteria of DIC before ERCP was performed but were diagnosed with DIC by a blood test $3 \mathrm{~h}$ after ERCP, and anticoagulant therapies were 
started.

\section{Measurements}

We retrospectively compared patients' background characteristics [age, sex, primary disease of cholangitis, severity of cholangitis, DIC score, systemic inflammatory response syndrome (SIRS) score, blood test values (platelet count (Plt), prothrombin time-international normalized ratio (PT-INR), fibrinogen (Fib), D-dimer, AT III, total bilirubin (T-bil), and C-reactive protein (CRP)), other anticoagulant drugs used, antibiotics used, procedures for papilla, and methods of biliary drainage], the DIC resolution rate, changes in DIC score, changes in SIRS score, changes in blood test values, AEs, and clinical outcomes between the rTM $(n=16)$ and rTM+AT groups $(n=40)$. DIC resolution was defined as a decrease in the DIC score to $\leq 3$ according to the DIC diagnostic criteria (15). The DIC score, SIRS score, and blood test values were expressed as the mean \pm standard deviation (SD).

This study was approved by the institutional review board of St. Marianna University School of Medicine (approval number: 3929).

\section{Statistical analyses}

A chi-square test, Fisher's exact test, and Welch's $t$-test were used for the statistical analyses where appropriate. A p value of $<0.05$ was regarded as significant. Statistical analyses were performed using the StatMate IV software program (ATMS, Tokyo, Japan).

\section{Results}

\section{Patients' background characteristics}

A comparison of patients' backgrounds between rTM and rTM+AT groups is shown in Table 1. Differences in age, sex, primary disease of cholangitis, severity of cholangitis, DIC score, SIRS score, other anticoagulant drugs used, antibiotics used, procedures for papilla, and methods of biliary drainage between the groups were not apparent (not significant; NS). Regarding blood test values, differences were not noted in the mean values of Plt, PT-INR, Fib, AT III, T-bil, and CRP (NS); however, the D-dimer level was 24.2 \pm 14.4 $\mu \mathrm{g} / \mathrm{mL}$ in the rTM group and $15.4 \pm 9.7 \mu \mathrm{g} / \mathrm{mL}$ in the $\mathrm{rTM}+$ AT group, showing a significantly higher value in the TM group $(\mathrm{p}=0.038)$.

\section{DIC resolution rate}

The DIC resolution rate on days 3/5/7/9 (when the day of DIC diagnosis and the beginning of treatment was defined as day 1) was $68.8 \%(11 / 16) / 100 \%(16 / 16) / 100 \%(16 / 16) /$ $100 \%(16 / 16)$ in the rTM group and $45.0 \%(18 / 40) / 65.0 \%$ $(26 / 40) / 90.0 \%(36 / 40) / 95.1 \%(38 / 40)$ in rTM+AT group, respectively. There were no marked differences in the DIC resolution rate between the groups on days 3 ( $\mathrm{p}=0.108), 7$ $(\mathrm{p}=0.460)$, or $9(\mathrm{p}=0.909)$, but the rate was significantly higher in the rTM group than in the rTM+AT group on day $5(\mathrm{p}=0.017)$.

\section{Changes in the DIC score}

In both groups, the DIC scores were significantly decreased on day 3 and thereafter compared to those on day 1 . The mean DIC scores at the time of the diagnosis did not differ markedly between the rTM $(5.31 \pm 1.30)$ and rTM+AT groups $(5.35 \pm 1.42 ; \mathrm{p}=0.923)$, but the scores on days $3,5,7$, and 9 were significantly lower in the rTM group $(2.75 \pm 1.06$, $1.00 \pm 0.68,0.69 \pm 0.85$, and $0.36 \pm 0.67$, respectively) than in the rTM+AT group $(3.75 \pm 1.72,2.65 \pm 1.78,1.40 \pm 1.55$, and $1.13 \pm 1.36$, respectively; $\mathrm{p}=0.012,<0.001,0.033,0.007$, respectively; Fig. 2).

\section{Changes in the SIRS score}

In both groups, the SIRS scores were significantly decreased on day 3 and thereafter compared to those on day 1 . Differences were not observed in SIRS scores on days 1, 3, 5 , 7, or 9 between the rTM group $(2.00 \pm 0.89,0.56 \pm 0.73$, $0.00 \pm 0.00,0.00 \pm 0.00$, and $0.00 \pm 0.00$, respectively) and rTM + AT group $(2.30 \pm 1.22,0.88 \pm 1.07,0.30 \pm 0.65,0.23 \pm 0.53$, and $0.18 \pm 0.51$, respectively; NS; Fig. 3).

\section{Changes in the blood test values}

Fig. 4 shows the changes in the blood test values of serum parameters between the rTM and rTM+AT groups. From days 1 to 9, the levels of Plt, PT-INR, D-dimer, T-bil, and CRP were significantly higher in the rTM group, while those of Plt, PT-INR, T-bil, and CRP were significantly higher in the rTM+AT group. Regarding markers of the coagulation system, the PT-INR levels were significantly lower in the rTM group than in the rTM+AT group on days 3 $(1.11 \pm 0.14,1.20 \pm 0.15 ; \mathrm{p}=0.044)$ and $9(1.12 \pm 0.08,1.19 \pm$ $0.14 ; \mathrm{p}=0.033)$. The AT III levels were significantly higher in the rTM+AT group than in the rTM group on days 3 $(57.60 \pm 8.13 \%, 85.72 \pm 16.39 \% ; \mathrm{p}<0.001)$ and $5(63.92 \pm$ $10.50 \%, 84.21 \pm 16.54 \%$; $<<0.001)$ but were not significantly different between the groups on day $9(66.57 \pm 10.98 \%$, $66.78 \pm 14.24 \%$; $\mathrm{p}=0.953)$. Regarding markers that reflected the AC status, the T-bil levels were significantly lower in the rTM group than in the rTM+AT group on days $3(1.91 \pm 1.32$ $\mathrm{mg} / \mathrm{dL}, 2.98 \pm 2.08 \mathrm{mg} / \mathrm{dL} ; \mathrm{p}=0.027), 5(1.56 \pm 1.47 \mathrm{mg} / \mathrm{dL}$, $3.16 \pm 2.93 \mathrm{mg} / \mathrm{dL} ; \mathrm{p}=0.010), 7(1.30 \pm 0.73 \mathrm{mg} / \mathrm{dL}, 3.03 \pm 3.47$ $\mathrm{mg} / \mathrm{dL} ; \mathrm{p}=0.005)$, and $9(1.15 \pm 0.56 \mathrm{mg} / \mathrm{dL}, 2.66 \pm 3.09 \mathrm{mg} /$ $\mathrm{dL} ; \mathrm{p}=0.005)$. The CRP levels were significantly lower in the rTM group than in the rTM+AT group on days $3(11.42$ $\pm 5.37 \mathrm{mg} / \mathrm{dL}, 14.63 \pm 5.35 \mathrm{mg} / \mathrm{dL} ; \mathrm{p}=0.048), 5(5.49 \pm 2.88$ $\mathrm{mg} / \mathrm{dL}, 8.64 \pm 4.68 \mathrm{mg} / \mathrm{dL} ; \mathrm{p}=0.004)$, and $7(3.18 \pm 2.74 \mathrm{mg} /$ $\mathrm{dL}, 5.43 \pm 3.57 \mathrm{mg} / \mathrm{dL} ; \mathrm{p}=0.025)$. The T-bil and CRP levels, which reflect the status of cholangitis, showed a correlation with changes in the DIC score.

\section{AEs}

The incidence of AEs related to the administration of rTM or AT was $6.3 \%(1 / 16)$ in the rTM group and $10.0 \%$ 
Table 1. Comparison of Patient Characteristics between RTM and RTM+AT Groups.

\begin{tabular}{|c|c|c|c|}
\hline & rTM group $(n=16)$ & rTM+AT group $(n=40)$ & $\mathrm{p}$ value \\
\hline Age $($ mean \pm SD) & $83.0 \pm 8.5$ & $77.6 \pm 10.2$ & 0.067 \\
\hline Sex (Male/Female) & $10 / 6$ & $29 / 11$ & 0.679 \\
\hline \multicolumn{4}{|l|}{ Primary disease } \\
\hline bile duct stone & 15 & 36 & 0.941 \\
\hline primary sclerosing cholangitis & 0 & 2 & \\
\hline IgG4-related sclerosing cholangitis & 1 & 0 & \\
\hline retrograde cholangitis & 0 & 2 & \\
\hline Severity of cholangitis (severe/moderate) & $13 / 3$ & $35 / 5$ & 0.856 \\
\hline DIC score $($ mean \pm SD) & $5.31 \pm 1.30$ & $5.35 \pm 1.42$ & 0.923 \\
\hline SIRS score $($ mean \pm SD) & $2.00 \pm 0.89$ & $2.30 \pm 1.22$ & 0.315 \\
\hline \multicolumn{4}{|l|}{ Other anticoagulant drugs } \\
\hline GM & 4 & 13 & 0.818 \\
\hline Ulinastatin & 2 & 0 & \\
\hline UFH & 0 & 1 & \\
\hline \multicolumn{4}{|l|}{ Antibiotics } \\
\hline MEPM & 15 & 30 & 0.221 \\
\hline $\mathrm{SBT} / \mathrm{CPZ}$ & 1 & 4 & \\
\hline DRPM & 0 & 5 & \\
\hline LVFX & 0 & 1 & \\
\hline \multicolumn{4}{|l|}{ Serum parameters (normal range) } \\
\hline Plt $\left(15.7-38.2 \times 10^{4} / \mu \mathrm{L}\right)$ & $10.3 \pm 5.7$ & $8.9 \pm 7.4$ & 0.457 \\
\hline PT-INR (0.9-1.2) & $1.28 \pm 0.19$ & $1.36 \pm 0.27$ & 0.218 \\
\hline Fibrinogen (200-400 mg/dL) & $494.3 \pm 223.1$ & $403.1 \pm 149.9$ & 0.148 \\
\hline D-dimer $(0-0.5 \mu \mathrm{g} / \mathrm{mL})$ & $24.2 \pm 14.4$ & $15.4 \pm 9.7$ & 0.038 \\
\hline ATIII $(75-125 \%)$ & $58.1 \pm 9.6$ & $55.1 \pm 8.5$ & 0.263 \\
\hline T-bil $(0.2-1.2 \mathrm{mg} / \mathrm{dL})$ & $3.2 \pm 1.6$ & $4.0 \pm 2.5$ & 0.158 \\
\hline $\mathrm{CRP}(<0.3 \mathrm{mg} / \mathrm{dL})$ & $16.7 \pm 6.1$ & $13.1 \pm 7.3$ & 0.086 \\
\hline Procedures for papilla & 4 & 6 & 0.620 \\
\hline EST & 3 & 6 & 0.954 \\
\hline Pre-cut & 1 & 0 & 0.632 \\
\hline Endoscopic transpapillary biliary drainage & 15 & 34 & 0.655 \\
\hline Endoscopic stone removal & 0 & 2 & 0.909 \\
\hline Percutaneous biliary drainage & 1 & 4 & 0.941 \\
\hline
\end{tabular}

rTM: recombinant human soluble thrombomodulin, AT: antithrombin, SD: standard deviation, DIC: disseminated intravascular coagulation, SIRS: systemic inflammatory response syndrome, GM: gabexate mesylate, UFH: unfractionated heparin, MEPM: meropenem, SBT/CPZ: sulbactam/cefoperazone, DRPM: dripenem, LVFX: levofloxacin, Plt: platelet count, PT-INR: prothrombin time-international normalized ratio, ATIII: antithrombin III, Tbil: total bilirubin, CRP: C-reactive protein, EST: endoscopic sphincterotomy

(4/40) in the rTM+AT group, showing no significant difference $(p=0.941)$. AEs included iliopsoas muscle hematoma in one patient in the rTM group and post-EST bleeding in two patients, iliopsoas muscle hematoma in one patient, and hemoptysis from Mycobacterium avium complex (MAC) in one patient in the rTM+AT group (Table 2). The patient who developed MAC hemoptysis had to discontinue rTM+ AT treatment. In the other patients, such bleeding events occurred after the administration period for rTM+AT. Two patients who developed an iliopsoas muscle hematoma were successfully treated by conservative therapy. In the two patients who developed post-EST bleeding, hemostasis was achieved by endoscopic hemostasis, although a blood transfusion was required.

\section{Outcomes}

The rate of in-hospital deaths was $0 \%(0 / 16)$ in the rTM group and $5.0 \%(2 / 40)$ in the rTM+AT group, showing no significant difference $(\mathrm{p}=0.909)$. In the $\mathrm{rTM}+\mathrm{AT}$ group, one patient died of exacerbation of acute cholangitis and DIC on day 30, and another patient recovered from DIC on day 7 but died of worsening heart failure on day 55 .

\section{Discussion}

Recently, the efficacy of anticoagulant therapy using rTM has been demonstrated for infection-induced DIC (1-4), with some reports describing the efficacy of combination therapy with rTM and AT (8). In Japan, DIC treatments using AT and/or rTM are common for patients with sepsis-induced 


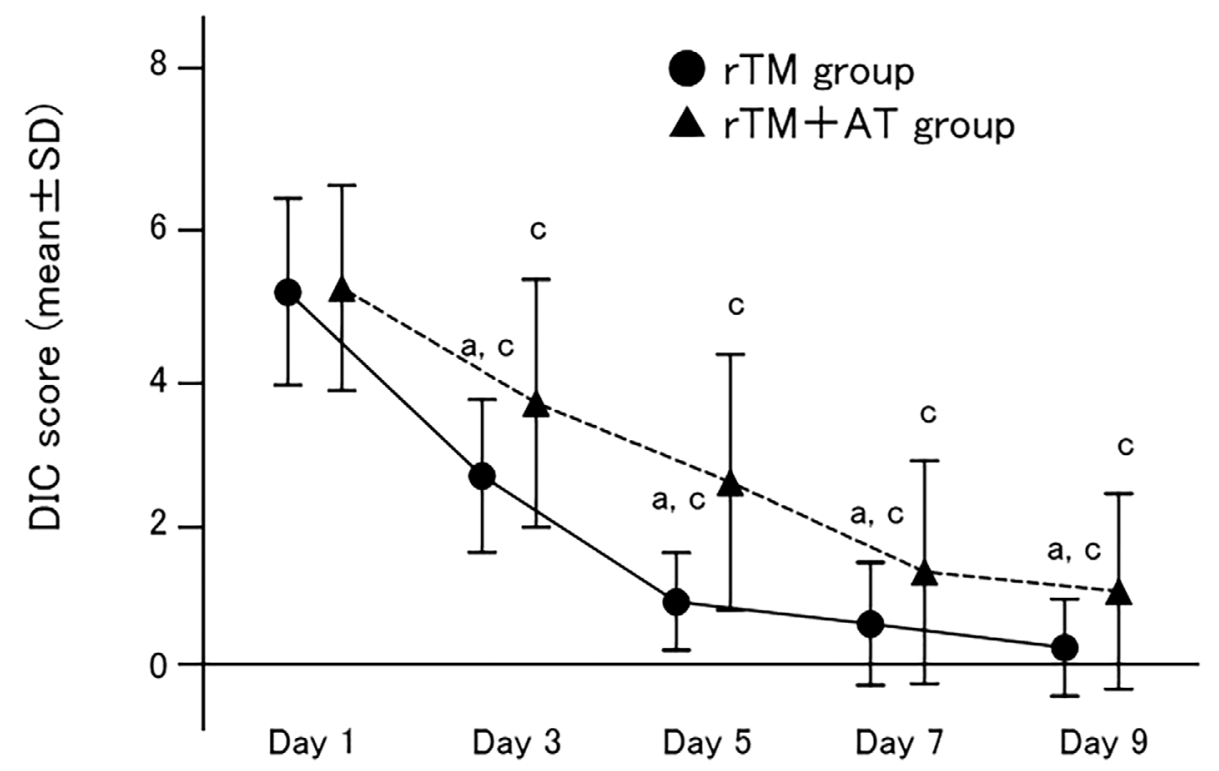

Figure 2. A comparison of the mean values of the DIC score between the rTM and rTM+AT groups. ${ }^{\mathrm{a}} \mathrm{p}<0.05$ vs. $\mathbf{r T M}+\mathrm{AT}$ group; ${ }^{\mathrm{c}} \mathbf{p}<0.05$ vs. baseline. DIC: disseminated intravascular coagulation, $\mathbf{r T M}$ : recombinant human soluble thrombomodulin, AT: antithrombin, SD: standard deviation

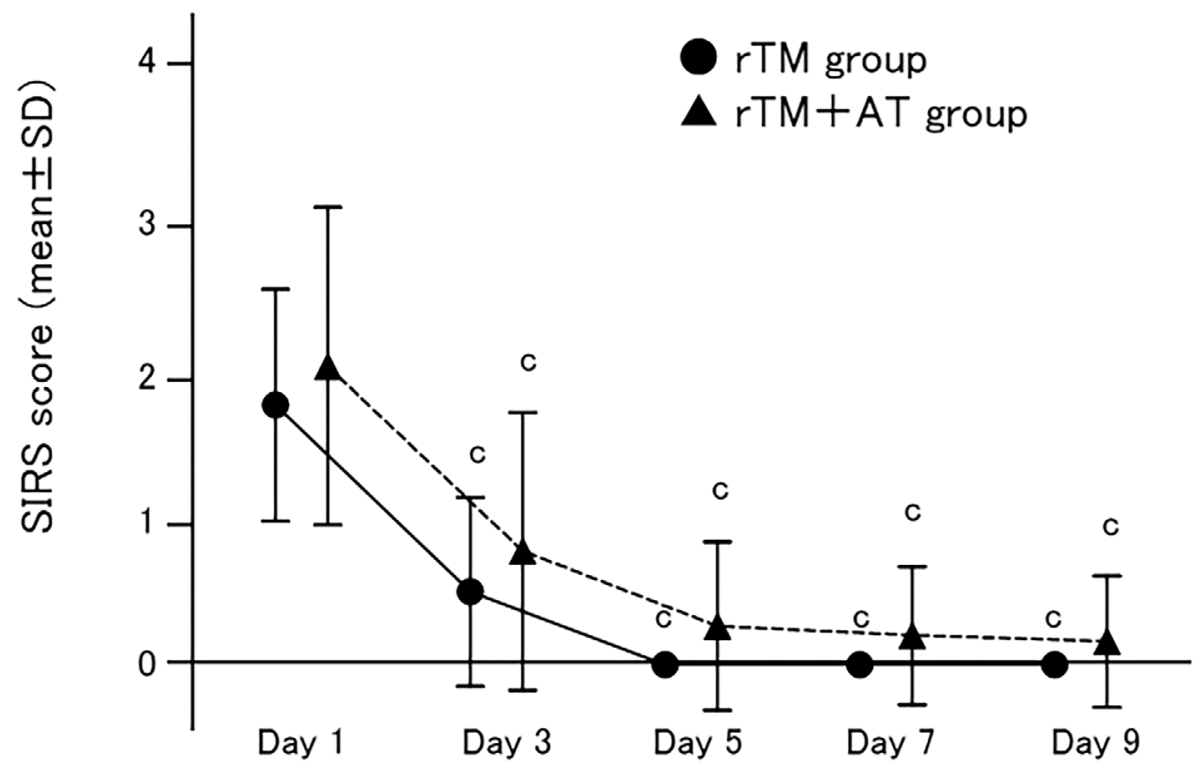

Figure 3. A comparison of the mean values of the SIRS score between the rTM and rTM+AT groups. ${ }^{\mathbf{c}} \mathbf{p}<0.05$ vs. baseline. SIRS: systemic inflammatory response syndrome, rTM: recombinant human soluble thrombomodulin, AT: antithrombin, SD: standard deviation

DIC. The TG18 for AC (12) were the first in the world to make a statement about anticoagulant therapy for ACinduced DIC and showed that the administration of rTM may be considered for severe cholangitis complicated with DIC, although the evidence level for this recommendation was low (level D). However, only a few reports on anticoagulant therapy for AC-induced DIC exist (9-11), so very little evidence exists that can form a basis for the selection of anticoagulant agents for this condition.

Treating the primary disease of DIC is most important point when managing infection-related DIC (16). In the case of AC, early biliary drainage usually leads to rapid improve- ment in DIC as well as AC. In a report from Suetani et al. (10), a multivariate analysis identified early biliary drainage as the only independent factor related to the improvement of DIC (OR: 12, 95\% CI: 2.3-60). Although a univariate analysis identified rTM administration as an independent factor related to the improvement of DIC (OR: 4.5, 95\% CI: 1.5-14), the need for anticoagulant therapy using rTM or AT in addition to early biliary drainage is unclear, and in particular, the necessity and safety of the concomitant use of AT with anticoagulant therapy using rTM are unclear.

In the present study, our analysis was limited to patients with benign diseases who underwent early biliary drainage, 

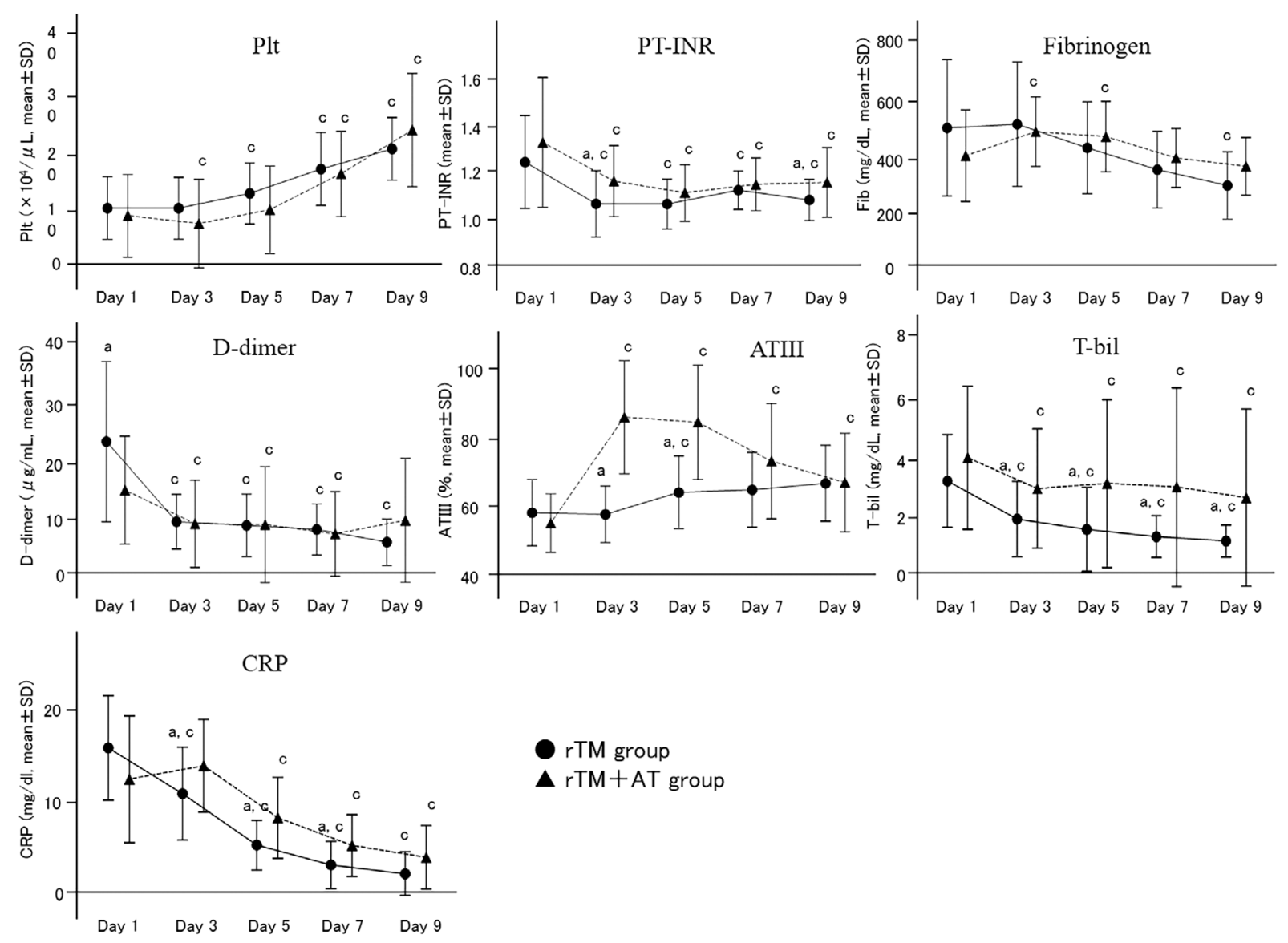

Figure 4. A comparison of mean values of serum parameters between the rTM and rTM+AT groups. ${ }^{a} \mathbf{p}<0.05$ vs. rTM+AT group; ${ }^{\mathrm{c}} \mathbf{p}<0.05$ vs. baseline. Plt: platelet count, PT-INR: prothrombin time-international normalized ratio, ATIII: antithrombin III, T-bil: total bilirubin, CRP: C-reactive protein, rTM: recombinant human soluble thrombomodulin, AT: antithrombin, SD: standard deviation

Table 2. Adverse Events.

\begin{tabular}{|c|c|c|c|c|c|c|c|c|}
\hline Case & Group & Adverse events & Onset & $\begin{array}{l}\text { Administration } \\
\text { periods of rTM }\end{array}$ & $\begin{array}{l}\text { Administration } \\
\text { periods of AT }\end{array}$ & Treatment & $\begin{array}{c}\text { Blood } \\
\text { transfusion }\end{array}$ & $\begin{array}{l}\text { Clinical } \\
\text { course }\end{array}$ \\
\hline 1 & $\mathrm{rTM}$ & $\begin{array}{l}\text { Iiopsoas muscle } \\
\text { hematoma }\end{array}$ & Day7 & 5 days & - & Conservatively & - & Improve \\
\hline 2 & $\mathrm{rTM}+\mathrm{AT}$ & $\begin{array}{c}\text { Iiopsoas muscle } \\
\text { hematoma }\end{array}$ & Day22 & 6 days & 3 days & Conservatively & - & Improve \\
\hline 3 & $\mathrm{rTM}+\mathrm{AT}$ & Post-EST bleeding & Day7 & 6 days & 3 days & $\begin{array}{l}\text { Endoscopic } \\
\text { hemostasis }\end{array}$ & + & Improve \\
\hline 4 & $\mathrm{rTM}+\mathrm{AT}$ & Post-EST bleeding & Day7 & 5 days & 3 days & $\begin{array}{l}\text { Endoscopic } \\
\text { hemostasis }\end{array}$ & + & Improve \\
\hline 5 & $\mathrm{rTM}+\mathrm{AT}$ & MAC hemoptysis & Day3 & 3 days & 3 days & $\begin{array}{c}\text { Discontinuation } \\
\text { of rTM }\end{array}$ & - & Improve \\
\hline
\end{tabular}

rTM: recombinant human soluble thrombomodulin, AT: antithrombin, MAC: mycobacterium avium complex

since previous reports have shown that patients who have not undergone biliary drainage (10) or those who develop malignant disease have a significantly worse outcome than those who do undergo drainage or who lack malignant disease (13). Our results indicated no extra benefit associated with the concomitant use of AT with anticoagulant therapy using rTM for AC-induced DIC. The DIC resolution rate on day 9 did not differ markedly between the rTM and rTM+
AT groups, and the DIC scores from days 3 to 9 were significantly lower in the rTM group than in the rTM+AT group. Regarding blood test values, the T-bil and CRP levels, which reflect the status of cholangitis, from days 3 to 9 were significantly lower in the rTM group than in the rTM+ AT group. This is the same pattern as the DIC score, suggesting that better control of cholangitis may contribute to an improvement in DIC. In addition, death due to AC and 
DIC occurred in only one patient in the rTM+AT group but in none of the patients in the rTM group. For the treatment of AC-induced DIC, controlling cholangitis by biliary drainage and anticoagulant therapy using rTM may be effective in improving DIC and the prognosis, whereas the addition of AT seemed unnecessary.

However, it should be borne in mind that the dose of AT administered in the present study was low (1,500 IU/day), and its treatment period was short (an average period of 3 days). The serum AT III value increased to approximately $85 \%$ in the rTM+AT group on days 3 and 5, which was significantly higher than in the rTM group, but decreased on day 7 and thereafter, reaching the same value in the rTM group on day 9. Hoffmann et al. (17) reported that keeping the AT value at $120 \%$ significantly improved abnormalities of blood coagulation. Furthermore, the KyberSept trial by Warren et al. (6) reported a good outcome by high-dose AT administration at 30,000 units/4 days. Although high-dose AT administration improved the treatment outcome, highdose therapy in Japan is not realistic. Furthermore, Iba et al. (18) reported that, if a patient's AT III value is lower than $40 \%$, the administration of AT at 3,000 IU/day is associated with a better prognosis than that at 1,500 IU/day. However, the patients in that study had sepsis-associated DIC. In contrast, for AC-induced DIC, biliary drainage and anticoagulant therapy with rTM alone may be sufficient because biliary drainage usually leads to the rapid improvement of AC as well as DIC. The pharmacological activity of rTM is reported to exert an anticoagulant effect independent of AT (19), and its treatment efficacy is expected in patients with a low AT value.

The incidence of AEs related to anticoagulant therapy did not differ markedly between the rTM and rTM+AT groups, suggesting that the concomitant use of AT may not increase the risk of AEs, such as bleeding. Of the five patients who developed bleeding, two required blood transfusion and endoscopic hemostasis; in all five patients, hemostasis was ultimately achieved without the development of any associated severe condition. However, in four of the five patients, bleeding occurred after the completion of anticoagulant therapy, suggesting that caution concerning potential bleeding should be practiced for this treatment, even after the completion of anticoagulant therapy.

Several limitations associated with the present study warrant mention. First, this was a retrospective study in a single institution. Second, the number of patients was small because of the rare nature of the subject disease and the strict inclusion criteria. Third, the decision concerning AT administration was made by the attending physician in each case. Fourth, the mean value of D-dimer was significantly higher in the rTM group than in the rTM+AT group. Further investigations in a large-scale, multicenter randomized control trial (RCT) will be required in the future. However, since DIC is a serious condition, it may be ethically difficult to plan an RCT, so we believe that this study contains useful information while examining with small number of cases.
Furthermore, since the subject of the present study had DIC induced by AC, patients with AC due to a malignant biliary stricture, in which malignancy-related DIC may be involved, were excluded. In actual clinical practice, AC secondary to malignant biliary stricture is commonly encountered. This suggests that the efficacy of combination therapy with rTM and AT for DIC associated with AC secondary to malignant biliary stricture needs to be investigated in future studies. In addition, the study was limited to patients who had undergone biliary drainage, but in actual clinical practice, cases exist where biliary drainage is difficult. Thus, the efficacy of combination therapy with rTM and AT for such cases needs to be investigated in further studies.

In conclusion, the concomitant use of AT with anticoagulant therapy using rTM for AC-induced DIC in patients who have undergone early biliary drainage or in those without malignancy may not help improve the treatment outcome.

The authors state that they have no Conflict of Interest (COI).

\section{References}

1. Saito H, Maruyama I, Shimazaki S, et al. Efficacy and safety of recombinant human soluble thrombomodulin (ART-123) in disseminated intravascular coagulation: results of a pase III, randomized, double-blind clinical traial. J Thromb Haemost 5: 31-41, 2007.

2. Aikawa N, Shimazaki S, Yamamoto Y, et al. Thrombomodulin alfa in the treatment of infectious patients complicated by disseminated intravascular coaglation: subanalysis from the phase 3 trial. Shock 35: 349-354, 2011

3. Vincent JL, Ramesh MK, Ernest D, et al. A randomized, doubleblind, placebo-controlled, Phase $2 b$ study to evaluate the safety and efficacy of recombinant human soluble thrombomodulin, ART123 , in patients with sepsis and suspected disseminated intravascular coagulation. Crit Care Med 41: 2069-2079, 2013.

4. Yamakawa K, Aihara M, Ogura H, Yuhara H, Hamasaki T, Shimazu T. Recombinant human soluble thrombomodulin in severe sepsis: a systematic review and meta-analysis. J Thromb Haemost 13: 508-519, 2015.

5. Kienast J, Juers M, Wiedermann CJ, et al. Treatment effects of high-dose antithrombin without concomitant heparin in patients with severe sepsis with or without disseminated intravascular coagulation. J Thromb Haemost 4: 90-97, 2006.

6. Warren BL, Eid A, Singer P, et al. Caring for the critically ill patient. High-dose antithrombin III in severe sepsis: a randomized controlled trial. JAMA 286: 1869-1878, 2001.

7. Hayakawa M, Saito S, Uchino S, et al. Characteristics, treatments, and outcomes of severe sepsis of 3195 ICU-treated adult patients throughout Japan during 2011-2013. J Intensive Care 4: 44, 2016.

8. Iba T, Hagiwara A, Saitoh D, et al. Effects of combination therapy using antithrombin and thrombomodulin for sepsis-associated disseminated intravascular coagulation. Ann Intensive Care 7: 110, 2017.

9. Nakahara K, Okuse C, Adachi S, et al. Use of antithrombin and thrombomodulin in the management of disseminated intravascular coagulation in patients with acute cholangitis. Gut Liver 7: 363370, 2013.

10. Suetani K, Okuse C, Nakahara K, et al. Thrombomodulin in the management of acute cholangitis-induced disseminated intravascular coagulation. World J Gastroenterol 21: 533-540, 2015.

11. Ito T, Nagahara A, Osada T, et al. Efficacy of recombinant human 
soluble thrombomodulin in patients with sepsis and disseminated intravascular coagulation in the gastroenterology field. Biomed Rep 3: 457-460, 2015.

12. Miura F, Okamoto K, Takada T, et al. Tokyo Guidelines 2018: initial management of acute biliary infection and flowchart for acute cholangitis. J Hepatobiliary Pancreat Sci 25: 31-40, 2018.

13. Tamura K, Saito H, Asakura H, et al. Recombinant human soluble thrombomodulin (thrombomodulin alfa) to treat disseminated intravascular coagulation in solid tumors: results of a one-arm prospective trial. Int J Clin Oncol 20: 821-828, 2015.

14. Kiriyama S, Takada T, Strasberg SM, et al. TG13 guidelines for diagnosis and severity grading of acute cholangitis (with videos). J Hepatobiliary Pancreat Sci 20: 24-34, 2013.

15. Gando S, Iba T, Eguchi Y, et al. A multicenter, prospective validation of disseminated intravascular coagulation diagnostic criteria for critically ill patients: comparing current criteria. Crit Care Med 34: 625-631, 2006

16. Wada H, Asakura H, Okamoto K, et al. Expert consensus for the treatment of disseminated intravascular coagulation in Japan. Thromb Res 125: 6-11, 2010.

17. Hoffmann JN, Mühlbayer D, Jochum M, Inthorn D. Effect of long-term and high-dose antithrombin supplementation on coagulation and fibrinolysis in patients with severe sepsis. Crit Care Med 32: 1851-1859, 2004

18. Iba T, Saitoh D, Wada H, Asakura H. Efficacy and bleeding risk of antithrombin supplementation in septic disseminated intravascular coagulation: a secondary survey. Crit Care 18: 497, 2014.

19. Aoki Y, Ohishi R, Takei R, et al. Effects of recombinant human soluble thrombomodulin (rhs-TM) on a rat model of disseminated intravascular coagulation with decreased levels of plasma antithrombin III. Thromb Haemost 71: 452-455, 1994.

The Internal Medicine is an Open Access journal distributed under the Creative Commons Attribution-NonCommercial-NoDerivatives 4.0 International License. To view the details of this license, please visit (https://creativecommons.org/licenses/ by-nc-nd/4.0/).

(C) 2019 The Japanese Society of Internal Medicine Intern Med 58: 907-914, 2019 